\title{
Procurando outros paradigmas para a educação
}

\author{
Maria Elizabeth Barros de Barros*
}

\begin{abstract}
RESUMO: Este artigo, inspirado nas propostas de Deleuze e Guattari, faz uma análise das práticas educacionais pautadas no paradigma cientificista. Propõe outras direções de sentido e um redimensionamento da educação com baser no paradigma ético/estético/ político trazendo a proposta das "Árvores do Conhecimento" de M. Authier e P. Levy como uma possibilidade de se construírem comunidades de conhecimento, recusando os especialismos.
\end{abstract}

Palavras-chave: Subjetividade, micropolítica, práticas educacionais

Recentemente, foi publicada no jornal Folha de S.Paulo a notícia de que um casal de médicos mineiros encaminhou para o Ministério da Educação um estudo, indicando que o problema da reprovação/evasão nas escolas brasileiras não é só de "fundo pedagógico". Afirmavam que o mais provável é que a reprovação no primeiro ano do ciclo básico se deva "à incapacidade congênita de um grande número de alunos de processar qualquer tipo de informação, déficit causado pela fome, sofrida desde o ventre materno, com graves seqüelas cognitivas e afetivas".

O estudo pede que se focalizem também as condições neurodesenvolvimentais do alunado e conclui: "Afinal, se parte do alunado, por deficiência que vem do ventre materno, não consegue absorver sequer o elementar, mais dificuldades terá com meios tecnológicos mais modernos".

Este é apenas um dentre vários outros artigos que tratam dessa temática, seja em jornais ou em livros sobre educação. Deparamo-nos, aí, com uma

Docente do Programa de Pós-graduação em Educação e do Departamento de Psicologia da Universidade Federal do Espírito Santo. E-mail: deppsi@ndp.ufes.br 
evidência: a educação é entendida, por vários autores ou pesquisadores da área, como mera mediadora do desenvolvimento do indivíduo, de sua felicidade e de seu bom desempenho como cidadão. A pedagogia e suas práticas não são, em muitas situações, entendidas como mecanismos de poder, ou seja, fábricas de subjetividade, máquinas de fazer falar, pensar e sentir.

A própria formação escolarizada é constituída por dispositivos que produzem e disciplinam a ordem pedagógica. Dispositivos que, como a punição e a recompensa articulados, os exames, as regras disciplinares, entre outros, ao se efetivarem no cotidiano das práticas escolares, colocam e recolocam, permanentemente, o alunado na lógica do funcionamento social dominante.

As pesquisas em Educação precisam mostrar a lógica dos dispositivos pedagógicos em ação, tentando analisar como certas crenças sobre a "idéia de homem" e de "realização humana", que fundamentam concepções hegemônicas no pensamento educacional brasileiro, são inércias fortemente encasteladas no campo pedagógico. Boa parte dos discursos e práticas no campo da educação nega que eles se constituem em operações produtoras de subjetividades ${ }^{1}$ e, portanto, não se limitam à função de mediadores do processo de "desenvolvimento dos indivíduos" ou de transmissão de conhecimentos objetivos. O papel produtivo/produtor da pedagogia tem ficado elidido, supervalorizando-se o que "falta" para que a educação no Brasil alcance os objetivos de "realização humana". Este parece constituir boa parte do ideário dos modos de subjetivação em curso no processo educacional.

A dimensão de pesquisa que estamos propondo é outra: considerar as teorias e práticas pedagógicas, colocadas em ação hoje, em seus efeitos de produção de subjetividade. Pesquisas que utilizem ferramentas teóricometodológicas que se expressem por meio de certas formas de interrogação e estratégias analíticas de descrição e que recusem a hermenêutica. Pesquisadores cartógrafos, ${ }^{2}$ que não se preocupam em transmitir o puro acontecimento, mas que incorporam os fatos à própria vida, para comunicá-los como sua própria experiência, deixando na pesquisa seu traço, "como a mão do artesão no vaso de argila".

Apostamos na afirmação de um pensamento que se apresente como problema, como multiplicidade dispersa, onde a pergunta não cessa de se mover e as respostas se transformam, incessantemente, em novas perguntas. Não se trata de procurar respostas universalizantes e totalizadoras, e sim de poder acompanhar movimentos do cotidiano educacional - na escola, na rua, na fábrica, enfim, nos diferentes espaços - e produzir um pensamento problematizante. Procurar provocar o debate, de forma que cada aspecto 
analisado se desdobre em infinitos pontos. Diríamos, como Nietzsche, que a interrogação é uma das formas de nos tornarmos "mestre e senhor de algo". Fazer crescer o desconhecimento como parte do conhecer.

As práticas educacionais e sua legitimação estão ancoradas no paradigma $^{3}$ da ciência moderna, o que significa trazer para a educação um determinismo, tanto no nível da produção dos conhecimentos quanto nos diferentes aspectos das relações institucionais. Sabemos que o paradigma da ciência moderna objetiva leis universais e tem como princípios básicos a cientificidade e a objetividade. A prioridade é dada à organização racional e ao conhecimento especializado. A idéia de evolução, progresso, linearidade finalista, representação e verdade estão na base da produção de conhecimentos neste paradigma.

Baseados na moralidade burguesa e libertos da religiosidade e da aristocracia, os princípios da ciência moderna pertencem à lógica cartesiana. O processo de legitimação dos conhecimentos produzidos estão, portanto, conectados com uma metodologia baseada na neutralidade científica. A elaboração teórica passa a ser coisa de especialistas e a "prática", dos técnicos. Conforme nos indica Rocha (1993), o projeto da burguesia era o enriquecimento da vida cotidiana por intermédio da cultura especializada, visando

ampliar a qualidade de vida e equalizar as condições gerais da população. Na verdade, foi o inverso que se produziu na história da sociedade ocidental: formação de um sistema fechado na racionalidade, auto-suficiente, onde o binômio racionalidade-futuro acabou por suplantar a emoção-presente; degradação do homem pelas novas condições de trabalho industrial; embate entre racionalidade dos meios e irracionalidade dos fins; consciência reificada de indivíduos cada vez mais submetidos às leis do capital; desenvolvimento tecnológico e promessas de qualidade de vida e abundância em oposição a desigualdade, sociedade de consumo e leis de mercado. (Rocha 1993, p. 7)

Na tentativa de superar o paradigma científico, novas formas de trabalhar e pesquisar vão se delineando no plano educacional. Novas tecnologias que apontam para uma linguagem da multiplicidade e para a crise de conceitos tão caros ao paradigma científico - como as noções de sujeito, identidade, razão e evolução/progresso -, desarmando, assim, esses princípios cientificistas.

Construir outro paradigma para a educação, redimensionar nossas práticas implicam, necessariamente, recusar os lugares fixos e as verda- 
des a serem descobertas, ocupando a posição de intelectual nômade, que desmonta verdades e faz toda afirmação ser provisória. As perspectivas cientificistas acabam por retirar a potencialidade da criação e da ruptura. Não há verdades a serem descobertas ou transmitidas, só existem máscaras e, se tudo é máscara, a possibilidade de mudança nos pertence.

Tal projeto não é niilista, talvez cético. Cético acerca das unidades dogmáticas, cético porque questiona as evidências, tentando abrir novas possibilidades para o pensamento/ação.

Uma proposta para a superação das práticas regidas pela lógica do capital, que homogeneiza e define universos existenciais cristalizados, inclui um método de análise e um princípio ontológico de superfície, uma filosofia da relação. Em vez de pensar uma prática educacional com base em objetos a ela relacionados, como por exemplo "o aluno", "o professor", "um método de ensino" e outros tantos, busca-se pensar a constituição dos objetos com base nessas práticas. A verdade não é, assim, uma adequação do pensamento a um determinado objeto e, dessa forma, a idéia de objeto natural, "trans-histórico", fica descartada. O que existe são relações de toda ordem, múltiplas e diferenciadas, vigentes numa determinada sociedade, num determinado momento histórico. É preciso evitar as narrativas unificadas para interpretação ou para mudança e recusar a postulação de uma natureza humana que alicerçaria nosso conhecimento ou nossas instituições sociais.

Tais possibilidades só se colocam se superarmos os discursos sistemáticos e universalistas que impregnam o ideário academicista, procurando a pluralidade e a singularidade das práticas, inventando formas específicas de experimentação que são transformadas continuamente.

Onde devem incidir nossos esforços para que os véus caiam e abramse possibilidades de outras máscaras? É preciso questionar o direito de universalizar o particular, de igualar as diferenças e a pretensão de abarcar a totalidade. A análise dos processos educacionais, ao sair de uma perspectiva exclusivamente macropolítica ${ }^{4}$ e privilegiando a dimensão micropolítica ${ }^{5}$ das práticas pedagógicas implementadas, abre um campo de possibilidades ilimitado, que nos permitirá desligar e desorganizar essa rede discursiva moral, em que se encontram hegemonicamente imersas as práticas pedagógicas.

Os modos de subjetivação, que as práticas educativas vêm instituindo, nem sempre ocorrem no sentido de potencializar as ações daqueles que são seus autores/atores, de forma que os processos educacionais se constituam como um projeto coletivo de produção de conhecimentos. O que se coloca em marcha no cotidiano educacional? 
A ordem social capitalista está sempre a demandar, para sua manutenção, a produção de homogeneidade. Esse processo de homogeneização efetiva-se por meio de estratégias-mecanismos, que impõem a ocupação de papéis, que devem estar conectados com as funções a serem desempenhadas. Nessa direção, as tecnologias pedagógicas passam a priorizar os processos que se apóiam num modelo ideal e perfeito de agir, naturalizando as diversas formas de vida. $O$ que tentamos indicar é a urgência de se construírem outros planos para o processo educacional, apoiados numa ética em que os saberes são construídos nas práticas. Nessa perspectiva ética não existem Bem e Mal como prescrições a priori, e sim análises imanentes às relações e que dependem, exclusivamente, dos aspectos que estão em questão. $O$ fundamental passa a ser, portanto, a possibilidade de selecionar o que fortalece, evitar o que possa enfraquecer a potência de criação e se negar a ser escravo de um conjunto de valores, não temendo o estranho e o inusitado.

O problema se coloca quando perdemos a dimensão do movimento de criação e nos restringimos ao plano moral, baseados em prescrições apriorísticas. Como superar os paradigmas instituídos na educação (baseados no cientificismo) e colocá-la no tempo da criação?

Algumas tentativas têm sido feitas no sentido de imprimir à escola um movimento que implica a construção de um outro "paradigma": um universo existencial que, ao recusar o cientificismo como modelo, privilegie a ética, a estética e o político. ${ }^{6}$

O trabalho de Pierre Levy e Michel Authier - As árvores do conhecimento - constitui uma dessas tentativas. Coloca em questão a perspectiva cientificista da educação em suas formas institucionalizadas e o ensino tradicional que pode ter como efeito a diluição das lutas coletivas cotidianas.

Consideram os autores que As árvores do conhecimento buscam colocar em xeque o totalitarismo e a intolerância à diversidade no âmbito da produção de conhecimentos. Esse trabalho objetiva, fundamentalmente, a construção de um espaço democrático, no qual se possa responder às exigências contemporâneas do saber, recusando o discurso da competência e da "qualidade total". Persegue o objetivo de inventar outras formas de produção de conhecimento, que procurem construir uma civilidade fundada em comunidades de aprendizagem e conhecimento. "Depois de décadas de individualismo, como encontrar uma solidariedade humana e concreta, sem, para tanto, sujeitar o indivíduo aos grupos sufocantes, às instituições hierárquicas ou às normas?" (Authier e Levy 1993, p. 17)

A proposta dos autores pretende pensar uma forma de aprender que considera o ritmo e a diversidade da sociedade contemporânea, escapando 
do poder dos especialistas e dos tecnocratas. A vitalidade da invenção e do pensamento coletivo é a sua utopia.

As árvores seriam intercessoras ${ }^{7}$ dos indivíduos de uma comunidade. O avanço da informática possibilita a criação de mecanismos que apresentam uma imagem gráfica dos saberes existentes em um determinado momento, num grupo que deles se utiliza. Os sujeitos passam a investir em situações de grupo, saindo do contato um a um (que marca as práticas escolares) e partindo para uma rede de diálogos, como um rizoma, ${ }^{8}$ de forma que a alteração em um dos seus pontos modifica todo o restante. Assim, esse método de conhecimento não se baseia em hierarquias, mas em conexões.

"As árvores do conhecimento" constituem-se numa outra forma de gestão dos saberes e de economia do conhecimento. O tédio do ensino tradicional, pautado nas exigências de objetividade, racionalidade e cientificidade, podem se desmanchar nos processos cotidianos coletivizados, buscando construir estratégias e instrumentos que possam ser suportes para mudanças importantes no domínio da educação.

A questão fundamental, sobre a qual está pautado o trabalho desses autores, é a de construir uma alternativa para se lidar com a velocidade do mundo contemporâneo, a sociedade de controle, ${ }^{9}$ analisando-a, desmanchando seus efeitos de perplexidade e descrença, evitando as burocracias, os especialismos, ${ }^{10}$ enfim, garantindo a processualidade e a vitalidade da invenção. Em vez do saudosismo, da romantização do passado ou de sentimentos de inabilidade para operar a realidade contemporânea, ter com ela uma relação de criação, produzindo subjetividades em ruptura com as modelizações capitalistas.

"As árvores do conhecimento" têm como finalidade cartografar os saberes dos diferentes grupos, viabilizando a construção desses saberes e dandoIhes visibilidade. Assim procedendo, constróem-se territórios democráticos que refundam as relações sociais, escapando do consumismo tecnológico. Os autores acreditam que nenhum indivíduo, isoladamente ou em grupos fechados, pode ter acesso ao conjunto dos conhecimentos, como ocorria nas sociedades passadas. As possibilidades que hoje se colocam são imensas e, portanto, é preciso aprender uns com os outros, sem excluir, a priori, nenhuma competência. Esse é o princípio das árvores do conhecimento: a abertura essencial e a dimensão coletiva do saber.

A proposta de Authier e Levy baseia-se, assim, em três princípios que, segundo eles, contrapõem-se aos da educação tradicional: 


\begin{tabular}{|c|c|}
\hline Árvores do conhecimento & Ensino tradicional \\
\hline 1) Cada um sabe & 1) Alguns entre nós são ignorantes \\
\hline 2) Não se sabe nunca & 2) Se possuo diploma eu sei \\
\hline 3) Todo saber está na humanidade & 3) Só há saber válido se reconhecido institucionalmente \\
\hline
\end{tabular}

Os princípios propostos pelos autores colocam em análise a forma de funcionamento da escola. Por que se privilegia essa forma de funcionamento?

Na nossa sociedade é a escola que evidencia o espaço do saber e confere aos indivíduos uma certa "identidade cognitiva". Entretanto, a forma como isso se faz, segundo os autores, exclui os saberes da vida, definindo, a priori, os conhecimentos considerados importantes para o sujeito e para a sociedade. Os saberes da vida não conferem diplomas, não são legitimados. Em lugar da busca, da invenção, persegue-se a certeza, a validação do saber, reificando-se conhecimentos e produzindo especialismos.

Por outro lado, "As árvores do conhecimento" não pretendem pôr em questão a importância da transmissão de conhecimentos sistematizados ao longo do processo de ensino. Pelo contrário, tal proposta visa pôr em evidência, tornar visíveis, saberes e conhecimentos mais amplos do que os contemplados pela escola. Ou seja, amplia-se o campo de ação da escola. Longe de ser identificada com as propostas antiinstitucionalistas dos anos 60/70, o que os autores pretendem é redimensionar o trabalho da escola e de outros espaços do saber, privilegiando uma outra ética para os processos educacionais.

Não há mais sentido em criar métodos para garantir o monopólio da formação do indivíduo mediante a seleção dos conhecimentos tradicionais reconhecidos exclusivamente no interior da vida acadêmica. Um novo espaço de aprendizagem e de engendramento de uma outra subjetividade não criará barreiras à livre circulação dos indivíduos no saber, mas permitirá que cada um se situe a cada momento no processo dando consistência a conhecimentos antes descontínuos. (Rocha 1996, p.187).

A proposta dos autores permite a criação de espaços, nos quais cada um dos membros de um determinado grupo (sala de aula, setor de uma empresa grupos de estudo, enfim, coletivos de indivíduos, institucionalizados ou não) inscreva-se e localize-se em um espaço de conhecimento efetivamente democrático.

Os instrumentos conceituais e técnicos criados fazem da proposta das árvores do conhecimento uma experiência viável e muito importante na 
tarefa de construir outros paradigmas para a educação, redefinindo os grupos humanos como comunidades de conhecimento e aprendizagem mútua.

Cada comunidade tem uma vida cognitiva singular e, portanto, cabe a ela decidir a forma da árvore que corresponde à sua realidade, as classificações de conhecimentos validados a priori não são consideradas. A árvore vai se transformando à medida que se transformam as competências da própria comunidade. As transformações da árvore evidenciam as tendências cognitivas da comunidade.

Nas comunidades de saber, cada indivíduo é considerado uma singularidade, e a comunidade, por sua vez, é uma composição de singularidades. Os saberes dos indivíduos são definidos por eles mesmos com base em suas experiências e seus conhecimentos. Ao se organizarem nas comunidades de saber, os indivíduos trazem os saberes até então adquiridos e seus desejos de aprendizagem, que podem ultrapassar as disponibilidades da comunidade. Assim sendo, uma comunidade de saber está atravessada pela diversidade social.

"As árvores do conhecimento" é uma proposta fundada em princípios de auto-organização, de democracia e de troca nas relações de saber. É o espaço organizado do conjunto dos signos das competências de uma dada comunidade.

Como exemplos de quadros de comunidade, os autores citam: os estabelecimentos de formação profissional conectados às empresas dos ramos correspondentes, os departamentos ou serviços da mesma organização, as associações de bairro e empresas da mesma zona urbana, vários estabelecimentos escolares da mesma academia, ou até mesmo de uma escola etc. Cada comunidade dessas pode ter sua própria árvore e seu próprio mecanismo de avaliação. Mas seria tudo isso verdadeiramente possível? Authier e Levy distinguem possibilidade técnica de possibilidade social. ${ }^{11}$

Tecnicamente, eles consideram que demonstram, mediante os princípios e o sistema proposto, a viabilidade material de uma árvore de conhecimento. Portanto, tecnicamente, ela não só é possível como, logicamente, existe.

A possibilidade social está relacionada com o interesse e o investimento dos cidadãos em geral em efetivar a proposta das comunidades do saber. Convocam as empresas, os estabelecimentos de ensino, as coletividades locais, as associações, os partidos políticos, os diferentes grupos e as pessoas que desejem contribuir para o desenvolvimento das árvores do conhecimento a que se unam para que, em conjunto, possam fazer das 
árvores do conhecimento "uma realidade humana e social, reunificar enfim a árvore do conhecimento à arvore da vida" (Authier e Levy 1993, p.168).

Para nós, a importância da análise de Authier e Levy sobre a escola é que tanto a construção de uma sociedade democrática, e de uma escola democrática, como a construção de outros modos de subjetividade dependem do agenciamento de múltiplos focos, de invenção e de singularização, ${ }^{12}$ que a proposta dos autores parece indicar.

O trabalho deles não pretende ser um modelo a ser seguido, mas indica possibilidades de luta. Busca idéias diferentes, inventar novas forças e novas armas. Talvez a questão, hoje, não se limite a lutar contra "a" dominação, mas, principalmente, estar atento às várias redes de poder que se configuram de forma incessante, investindo de maneira a argüi-las e desmanchá-las. Precisamos ser mais criativos que as máquinas de subjetivação capitalista.

Não se trata de construir modelos, de propor soluções sociais de longo alcance nem de oferecer linhas de ação, mas de tentar pensar e repensar as lutas no campo social.

Como administrar a crise em que vivemos? A experimentação talvez seja uma via. Não temos nem queremos marcos instituídos para trabalhar. Como nos lembra Deleuze, inspirado em Godard, não desejamos idéias justas, mas justo idéias.

\section{Notas}

1. Subjetividade aqui não se refere a totalizações ou centralizações no indivíduo. $O$ termo, da forma como o utilizamos, refere-se aos modos de existência fabricados e modelados no registro social, não se colando à idéia de indivíduo.

2. Cartografia refere-se a desenhos que acompanham e se constituem ao mesmo tempo em que os movimentos de transformação das paisagens psicossociais se dão. "A cartografia, nesse caso, acompanha e se faz ao mesmo tempo que o desmanchamento de certos mundos - sua perda de sentido - e a formação de outros: mundos que se criam para expressar afetos contemporâneos, em relação aos quais os universos vigentes tornaram-se obsoletos." (Rolnik 1989, p. 15).

3. Paradigma é uma palavra de origem grega que significa exemplo, padrão a ser seguido. Nos seus diferentes usos, o termo representa código, lei, que, como referência, serve à organização e atribuição de sentidos à realidade.

4. Macropolítico refere-se ao plano dos territórios demarcados, das unidades constituídas recortando sujeitos e definindo-os por oposição binária, por exemplo: alunoprofessor, homem-mulher, jovem-velho, orientador-professor. O Plano macropolítico não eqüivale a "grande" e sim às realidades constituídas 
5. Micropolítica refere-se ao plano das afecções onde não há unidades, apenas intensidade. Fala do processo, de como reproduzimos, ou não, os modos de subjetividade dominante. Portanto, no sentido que está sendo empregado não se refere a "menor" ou "pequeno".

6. Guattari propõe a expressão paradigma ético-estético-político para se contrapor ao paradigma científico. Estético porque criação permanente, subvertendo a pretensa unidade do mundo capitalista; ético porque potência ativa que surge na imanência das práticas para coordenar a vida e escolher a forma de vivê-la, e político porque implica a escolha de modos de mundo que se quer viver.

7. Os intercessores estão "entre", estão de passagem e se conectam com fragmentos para que outras possibilidades de ação possam se constituir.

8. O conceito filosófico de rizoma é de Deleuze e Guattari. Baseados na botânica, definem o rizoma como um tipo de raiz que se espalha para todos os lados.

9. Deleuze considera que hoje vivemos a sociedade de controle que, diferentemente dos confinamentos que são moldes, como uma moldagem, "os controles são uma modulação, como uma moldagem autodeformante que mudasse continuamente, a cada instante, ou como uma peneira cujas malhas mudassem de um ponto a outro. Assim, as sociedades de controle, que estão substituindo as sociedades disciplinares, são formas ultra-rápidas de controle ao ar livre que substituem as antigas disciplinas que operavam na duração de um sistema fechado (Deleuze 1992, pp. 220-221).

10. Estamos chamando de especialismos a uma supervalorização de determinados saberes em detrimento de outros; referem-se, portanto, ao uso de uma determinada especialidade como forma de desqualificação do saber do outro e concentração do poder do saber nas mãos de alguns, dos autodenominados especialistas.

11. Os autores colocam no livro o endereço para que aqueles que desejarem implantar as árvores do conhecimento possam entrar em contato com eles. (Ver nas referências bibliográficas a indicação do livro).

12. Os processos de singularização implicam produção da diferença, ruptura com a homogeneidade, de forma que a organização do cotidiano escape dos padrões dominantes.

Recebido para publicação em Março de 1999.

\title{
Searching for other paradigms for education
}

\begin{abstract}
This article, inspired by the proposal of Deleuze and Guattari, analyses the educational practices supported by the scientific model. It proposes other educational sense directions and dimensions based on the ethical/esthetic/politic principle, according to M. Authier's and P. Levy's "Tree Knowledge" as a way to construct knowledge communities, refusing the traditional educational scientificism.
\end{abstract}




\section{Bibliografia}

ATHAYDE, M. "Processo produtivo, espaço educativo: Um campo de lutas". Dissertação de mestrado em Educação, João Pessoa: UFB, 1988.

AUTHIER, M. e LÉVY, P. Les arbres des connaissances. Paris: La Découverte, 1993.

BARROS, M.E. de. "A formação do psicólogo: O estágio como etapa essencial deste processo". Dissertação de mestrado em Psicologia Escolar. Rio de Janeiro: UGF, 1980.

. A transformação do cotidiano: A formação do educador, a experiência de Vitória. Vitória: Edufes,1997.

BAUDELOT, C. e ESTABLET, R. L'école capitaliste en France. Paris: Maspero, 1972.

BRANDÃO, C.R O que é educação. São Paulo: Brasiliense, 1982.

COSTA, J. F. Ordem médica e norma familiar. Rio de Janeiro: Graal, 1983.

DELEUZE, G. Conversações. Rio de Janeiro: 34, 1986.

DONZELOT, J. A polícia das famílias. Rio de Janeiro: Graal, 1980.

EVRARD, P. "Las manos Puras". Análisis institucional y socioanálisis. México: Nueva Imagen, 1977.

FOUCAULT, M. Vigiar e Punir. Rio de Janeiro: Vozes, 1983.

GRAMSCI, A. Os intelectuais e a organização da cultura. Rio de Janeiro: Civilização Brasileira, 1991.

LAPASSADE, G. et al. El análisis institucional (Por un cambio de las instituciones). Madri: Campo Abierto, 1977.

ROCHA, M. L. de. "Do tédio à cronogênese: $O$ engendramento de um modo de subjetivação no processo educacional". Projeto de tese de doutoramento apresentado ao Programa de Pós-graduação em Psicologia Clínica, PUC-SP, 1993.

. "Do tédio à cronogênese: Uma abordagem ético-estético-política da prática escolar". São Paulo, 1996. Tese de doutoramento. PUCSP, 1996

ROLNIK, S. Cartografia sentimental: Transformações contemporâneas do desejo. São Paulo: Estação Liberdade, 1989. 